\title{
FORMAÇÃO DOCENTE DE LÍNGUA PORTUGUESA: UM TEXTO EM ANÁLISE DISCURSIVA
}

\author{
Tainá Almeida* \\ Lúcia Gracia Ferreira* \\ Lucimar Gracia Ferreira ${ }^{* * *}$
}

RESUMO: Este artigo foi realizado a partir da perspectiva da Análise do Discurso Bakhtiniana (BAKHTIN, 2002) e da Análise do Discurso Crítica (FAIRCLOUGH, 1996, 2001) em diálogo com autores da área de educação. Trata-se de uma análise discursiva do artigo de opinião de Marcos Bagno intitulado "A catástrofe dos cursos de Letras", onde discutimos o contexto de produção discursiva; o discurso, suas escolhas lexicais e efeitos de sentido; e a formação do professor de Língua Portuguesa. Buscamos analisar o discurso do autor do texto em questão a partir das duras críticas realizadas por ele à formação de professores no curso de Letras, bem como refletir acerca da atual situação da formação docente e ensino de Língua Portuguesa no Brasil. O texto analisado alcança o seu objetivo de chamar a atenção do leitor-alvo e suscita reflexões a partir dos ditos e não-ditos nele presentes quando analisados a partir do estatuto do explícito e implícito (DUCROT, 1984).

PALAVRAS-CHAVE: Discurso; Formação docente; Língua Portuguesa.

\section{Introdução}

Como docentes licenciadas em Letras Vernáculas, as temáticas da formação do professor e da qualidade da educação nos intrigam e interessam. Ainda na nossa formação, nos deparamos com um texto escrito pelo afamado linguista Marcos Bagno intitulado "A catástrofe dos cursos de Letras”. Bastante direto e com uma crítica contumaz, seu curto texto provocou em nós reflexões que nos levaram à construção deste artigo.

\footnotetext{
* Doutoranda em Língua e Cultura pela Universidade Federal da Bahia (Ufba). Mestre em Letras: Cultura, Educação e Linguagens pela Universidade Estadual do Sudoeste da Bahia

${ }^{* *}$ Doutora em Educação pela Universidade Federal de São Carlos (UFSCar). Professora Adjunta da Universidade Federal do Recôncavo da Bahia (UFRB)/Centro de Formação de Professores. Professora Permanente do Programa de Pós-Graduação em Educação da Universidade Federal da Bahia (UFBA). Realizou estágio de pós-doutorado em Educação pela Universidade Federal da Bahia (Ufba). Realizou estágio de pós-doutorado em Letras pela Universidade Estadual do Sudoeste da Bahia (Uesb).

*** Mestre em Educação pela Universidade pela Universidade Estadual do Sudoeste da Bahia (Uesb). Integrante do Grupo de Pesquisa e Estudos Pedagógicos (GPEP).
} 
Por se tratar de um artigo de opinião e conter críticas ferrenhas ao sistema educacional brasileiro - tanto o básico como o superior, especificamente o de formação de professores de Língua Portuguesa (LP) - realizadas por meio de metáforas, comparações e adjetivações fortes, consideramos ser esse um texto rico para análise discursiva. Além disso, o tema discutido é de interesse direto dos estudantes e docentes do curso de Letras e possui questões controversas e generalistas que facilmente podem provocar reflexões pertinentes em nossa área.

As discussões empreendidas neste artigo estão baseadas nas teorias da Análise do Discurso (AD) Bakhtiniana e da Análise do Discurso Crítica (ADC) em diálogo com autores da área de educação. Assim, a AD examina as condições de produção dos discursos, os sujeitos falantes, os receptores, o tempo e o lugar, a cultura, os símbolos, os valores e os aspectos socioeconômicos e histórico-políticos em que o discurso foi produzido (BRANDÃO, 2005).

A $\mathrm{AD}$, além de ser uma teoria dialógica da linguagem - portanto, conhecimento específico do curso de Letras -, é necessária aos egressos do curso para sua carreira profissional, afinal, o lugar do ensino é carregado de práticas discursivas e no processo de ensino e aprendizagem estas se encontram em todos os lugares, podendo ser analisadas e interpretadas. Objetivamos, assim, analisar o discurso do autor do texto em questão a partir das duras críticas realizadas por ele à formação de professores no curso de Letras, bem como refletir acerca da atual situação da formação docente e ensino de Língua Portuguesa no Brasil. 


\section{O texto em questão: $A$ catástrofe dos cursos de Letras}

\section{A catástrofe dos cursos de Letras}

Marcos Bagno

Linguista, escritor, tradutor e professor da UNB

A formação dos professores de português, hoje, no Brasil, é uma catástrofe. Nós, os responsáveis pelos cursos de Letras, não enxergamos a bomba-relógio que temos nas mãos. As estatísticas não mentem: a retumbante maioria dos estudantes de Letras vêm de camadas sociais pobres ou mesmo miseráveis, filhos de pais analfabetos ou que têm escolarização inferior a quatro anos. Isso significa muita coisa. Significa que esses estudantes têm um histórico de letramento muito reduzido: no ambiente familiar, não convivem com a cultura letrada, não têm acesso a livros, revistas, enciclopédias etc. Significa que não são falantes das normas urbanas de prestígio (as mesmas que supostamente terão de ensinar a seus futuros alunos) e têm domínio escasso da leitura e da escrita. Só na faculdade é que a maioria deles vai ler, pela primeira vez na vida, um romance inteiro ou um texto teórico. Vêm, quase todos, do ensino público, essa tragédia ecológica brasileira muito pior que as queimadas na Amazônia.

Nós, porém, fingimos que eles são ótimos leitores e redatores, e despejamos sobre eles, logo no primeiro semestre, teorias sofisticadas, que exigem alto poder de abstração e familiaridade com a reflexão filosófica, e textos de literatura clássica, escritos numa língua que para eles é quase estrangeira. E assim vamos nos iludindo e iludindo os estudantes.

O resultado é que os estudantes de Letras saem diplomados sem saber lingüística, sem saber teoria e crítica literária e sem saber escrever um texto acadêmico com pé e cabeça. Todos os dias, recebo mensagens de formandos que me pedem orientação para seus trabalhos finais. Alguns até me enviam seus projetos. São textos repletos de erros primários de ortografia, pontuação, sintaxe, vocabulário, com frases truncadas e sem sentido. Assim eles chegam ao final do curso, e suas monografias, mal escritas, sem nenhum rigor teórico ou metodológico, são aprovadas alegre e irresponsavelmente por seus supostos orientadores.

O problema, é claro, não está no fato (que merece comemoração) de acolhermos na universidade alunos vindos das camadas mais desfavorecidas da população. O problema é não oferecermos a eles condições de, primeiro, se familiarizar com o mundo acadêmico, que lhes é totalmente estranho, por meio de cursos intensivos (e exclusivos) de leitura e produção de textos, de muita leitura e muita produção de textos, para só depois desses (no mínimo) dois anos de preparação eles poderem começar a adentrar o terreno das teorias, das reflexões filosóficas, da alta literatura. Se não fizermos isso urgentemente (anteontem!), as salas de aula do ensino básico estarão ocupadas por professores que, mal sabendo ler e escrever adequadamente, não poderão desempenhar sua principal tarefa: ensinar a ler e a escrever adequadamente! Não sei, aliás, por que escrevi “estarão ocupadas”: elas já estão ocupadas, neste momento, por essas pessoas, de quem se cobra tanto e a quem não se oferece uma formação docente que também seja, minimamente, decente.

\section{O contexto de produção discursiva}

Primeiramente, a fim de compreendermos de que lugar de fala o autor emite seu discurso, o texto escolhido, enquanto manifestação verbal discursiva, precisa ser analisado levando em conta seu contexto sócio-histórico de produção.

O ano em que foi escrito, final de 2008, é o oitavo ano de vigência do Plano Nacional de Educação (PNE) instituído pela Lei Nº 010172/2001. Dentre os objetivos educa- 
tivos apontados por esse documento, havia uma meta referente à política nacional de formação e valorização dos profissionais da educação que buscava assegurar que, ao final de 10 (dez) anos, 70\% dos professores da educação básica possuíssem formação específica de nível superior.

No ano posterior à escrita do texto de Bagno, foi instituída a promoção da oferta emergencial de cursos de licenciaturas e de cursos ou programas especiais dirigidos aos docentes em exercício há pelo menos três anos na rede pública de educação básica, que sejam:

a) graduados não licenciados;

b) licenciados em área diversa da atuação docente; e

c) de nível médio, na modalidade Normal. (BRASIL, 2009, p. 6)

Assim, nesse período, houve um aumento significativo no número de programas de formação de professores, bem como instituições e cursos superiores em regime de educação à distância (EaD). Entretanto, devido à demanda, aos prazos e à oferta desses cursos, a qualidade do ensino superior passou a ser muito questionada. Corrobora com esse contexto o fato do Programa Internacional de Avaliação de Estudantes (PISA), uma avaliação educacional a nível mundial, ter mostrado a partir de seus resultados do ano de 2006 que a Educação do Brasil ocupa num ranking de 57 países a 50a colocação em leitura e que, apesar de ter melhorado em relação à avaliação anterior, o desempenho brasileiro ainda está longe de ser uma educação de qualidade. Vale dizer que alguns esforços foram empreendidos visando à melhoria desse quadro, como, por exemplo, a ampliação realizada em 2009 do Programa Institucional de Bolsa de Iniciação à Docência (Pibid) que havia sido implantado dois anos antes.

Dessa forma, observamos que o contexto de produção do texto em análise era o de grande deficiência na formação de professores, tanto no sentido político quanto em relação à qualidade da formação, enquanto, paralelamente, havia genuína exigência de que os professores graduados em Letras fossem linguisticamente competentes - saibam falar, ler, interpretar e escrever bem. Essa breve leitura contextual revela que o texto de Bagno representa uma crítica reflexiva pertinente à situação educativa à época - e ainda o é 11 (onze) anos despois - no que concerne à formação e atuação dos professores de LP. Afinal, as críticas por ele realizadas possuem embasamentos estatísticos que ratificam as deficiências 
desse curso de formação e, consequentemente, da prática docente dos professores de português na educação básica de modo geral.

Embora respaldadas por dados científicos e empíricos, as críticas de Bagno evocam consternação no leitor pelas escolhas vocabulares que ele faz, as quais revelam seu lugar discursivo e ideológico de fala e produzem diferenciados efeitos de sentido.

\section{O discurso do autor em análise: escolhas lexicais e efeitos de sentido}

Segundo Bakhtin (2002, p. 36), "a palavra é o fenômeno ideológico por excelência". Com essa afirmação, o autor esclarece o poder que tem a linguagem e a interação que ela proporciona aos indivíduos enquanto seres sociais. A palavra tem o poder de estabelecer sistemas de ideias e de desestruturá-los também. Ela é essencialmente política e ideológica. Dessa forma, analisar o discurso elaborado por determinado grupo, indivíduo ou instituição é o meio mais eficaz para se apreender suas ideologias, pois é lá onde elas eminentemente se materializam.

Fairclough (1996) afirma que o discurso é uma prática social que não apenas representa o mundo, mas que o faz significar, que o constitui e o constrói com base nos significados. A vida humana é essencialmente narrativa. A forma como narramos e interpretamos os fenômenos que nos acontecem é o que lhes confere significado e não necessariamente os acontecimentos em si. Por isso é que uma mesma situação vivenciada por pessoas distintas terá significados igualmente distintos para cada uma. Ou seja, o discurso, ao mesmo tempo em que nos representa (é o modo como nos expressamos), nos constitui (é a lente pela qual enxergamos o mundo). Em consonância com esse pensamento, o linguista indiano Kumaravadivelu (2008, p. 140) diz que

[o] discurso designa o território conceitual inteiro no qual o conhecimento é produzido e reproduzido. Inclui não somente o que é, na verdade, pensado e articulado, mas também determina o que pode ser dito ou ouvido e o que é silenciado, o que é aceitável e o que é tabu. 
Assim, a linguagem não pode ser vista como um instrumento neutro, pois ela não apenas media a comunicação entre as pessoas, mas veicula ideologias. Como dito, o discurso é, por natureza, ideológico. E, conforme Fairclough (2001), as ideologias, como sentidos e significações da realidade, são materializadas nas práticas discursivas, contribuindo para a produção, reprodução ou transformação das relações de hierarquia, opressão e dominação entre as classes sociais. Relacionando os conceitos de língua, discurso e ideologia, Orlandi (2007, p. 297) esclarece:

Há um princípio discursivo que diz que não há discurso sem sujeito e não há sujeito sem ideologia. O discurso é o lugar em que podemos observar a articulação entre língua e ideologia. A materialidade específica da ideologia é o discurso e a materialidade específica do discurso é a língua.

Cada sujeito social, pelas posições socioculturais que ocupa, se insere em diferentes formações discursivas dentro das quais os efeitos de sentido se constituem de forma distinta. As formações discursivas "se definem como aquilo que o sujeito pode e deve dizer numa situação dada em uma conjuntura dada, e refletem, no discurso, as formações ideológicas" (ORLANDI, 2007, p. 296). Se falo, por exemplo, de uma escola para todos inclusiva, que acolha as camadas populares e alunos com necessidades educacionais especiais - dentro da formação discursiva "política educacional", temos um sentido, se esse mesmo tópico for inserido na formação discursiva “docentes do curso de Letras", teremos outro sentido. Como prática simbólica, o discurso toca de tal maneira nossas práticas sociais que o fato de ser pobre e advir de uma classe social menos favorecida pode determinar o tipo de tratamento a ser recebido num mesmo ambiente social, como a escola ou a universidade.

Dessa maneira, as escolhas lexicais que realizamos ao operar a língua e construir textos - sejam eles orais ou escritos - revelam nossas formações discursivas e as ideologias que lhes dão suporte. Lepschy (1984, p. 162) disse que “[a] diferente estruturação lexical corresponde a uma diversidade de concepções e ideologias" e, por isso, o léxico que mobilizo no momento da produção textual - os adjetivos que escolho para qualificar o objeto discursivo, o tempo verbal empregado, os pronomes escolhidos e a disposição na frase etc. 
- são materializações do discurso e produzem efeitos de sentido distintos relacionáveis a ideologias específicas. Afinal, como disse Bakhtin (2002, p. 95): "Na realidade, não são palavras o que pronunciamos ou escutamos, mas verdades ou mentiras, coisas boas ou más, importantes ou triviais, agradáveis ou desagradáveis etc. A palavra está sempre carregada de um conteúdo ou de um sentido ideológico ou vivencial".

Diante do exposto, constatamos que o referido texto de Marcos Bagno é político, como toda enunciação o é, e se configura como o espaço discursivo no qual o autor se posiciona ideologicamente quando constrói sua argumentação discursiva - radical, para alguns - referente à educação pública e à graduação em Letras, mais especificamente. Isto pode ser facilmente percebido nas escolhas lexicais do autor evidenciadas nos excertos seguintes (grifo nosso):

i. "A formação dos professores de português, hoje, no Brasil, é uma catástrofe."

ii. "Vêm, quase todos, do ensino público, essa tragédia ecológica brasileira muito pior que as queimadas na Amazônia."

iii. "E assim vamos nos iludindo e iludindo os estudantes."

Os vocábulos utilizados pelo autor parecem ter sido propositalmente escolhidos a fim de provocar no leitor a indignação e o choque como efeitos de sentido. As metáforas da "catástrofe" e da "tragédia ecológica" conduzem o leitor à imaginação de cenários desastrosos como comparação ao sistema escolar brasileiro e o emprego do verbo "iludir" denuncia com clareza o que o autor considera como resultado da nossa educação: a criação de uma fantasia de ensino e de aprendizagem. Claramente, Bagno se insere na formação discursiva do docente crítico, inconformado com os resultados de um sistema obsoleto de educação.

Embora munido de conhecimento científico e empírico do assunto que trata no texto, Bagno apela para generalizações que podem, evidentemente, incorrer em erros. Os trechos em que isso ocorre podem ser vistos aqui abaixo (grifo nosso):

iv. "Significa que esses estudantes têm um histórico de letramento muito reduzido: no ambiente familiar, não convivem com a 
cultura letrada, não têm acesso a livros, revistas, enciclopédias etc. Significa que não são falantes das normas urbanas de prestígio (as mesmas que supostamente terão de ensinar a seus futuros alunos) e têm domínio escasso da leitura e da escrita."

v. "O resultado é que os estudantes de Letras saem diplomados sem saber lingüística, sem saber teoria e crítica literária e sem saber escrever um texto acadêmico com pé e cabeça."

Para analisarmos esses trechos, precisamos nos lembrar de que cada item lexical selecionado para análise mobiliza uma memória discursiva particular que evoca efeitos de sentido capazes de indiciar quais fios ideológicos estão implícitos nas escolhas autorais abordadas. Ao se escolher determinado termo ou palavra, aquele que o faz mobiliza, naquele instante, memórias discursivas que provocam efeitos de sentido variáveis - pois dependem necessariamente da comunidade discursiva de onde e para a qual se fala/discursiviza. O léxico empregado referencia algo que se quer (ou não) dizer. Sobre essa ação, explica Ducrot (1984, p. 419):

Mas, desde que haja um acto de fala, um dizer, há uma orientação
necessária para aquilo que não é o dizer. É a esta orientação que
podemos chamar "referência", chamando "referente" ao mundo ou
objecto que ela pretende descrever ou transformar. (O referente de
um discurso não é [...] a realidade mas sim a sua realidade, isto é, o
que o discurso escolhe ou instrui como realidade)

Ao afirmar que os estudantes oriundos das camadas populares não convivem no ambiente familiar "com a cultura letrada, não têm acesso a livros, revistas, enciclopédias", nem "são falantes das normas urbanas de prestígio" e "saem diplomados sem saber lingüística", Bagno realiza uma generalização e o problema da generalização, conforme Ferrés (1998), não é que a informação que lhe deu origem não tenha sido retirada da realidade objetiva e concreta, ou seja, que ela seja verdadeira. O problema é que "[...] toda generalização simplificadora pressupõe uma traição a uma realidade que é necessariamente complexa, contraditória, dual” (FERRÉS, 1998, p. 136). Com isso, colocando a "retumbante maioria" dos alunos de Letras num lugar subalterno, ele gera ofensas para alguns e reflexões 
para outros. Mas é fato que o texto chama atenção para a formação do professor de Português no Brasil e suas lacunas formativas que geram uma imagem de qualidade inferior do curso de Letras.

Mesmo num texto com construções tão claras e escolhas lexicais de forte impacto, uma análise discursiva deve sempre observar o dito e o não-dito, o sentido explícito e o implícito. Ducrot (1984, p. 394) argumenta que

[...] o léxico e mesmo a sintaxe veiculam toda a espécie de crenças e conhecimentos que são introduzidos no discurso pelo próprio fato de se utilizar a língua. Numa palavra, o sentido "explícito" constitui apenas um nível da semântica das línguas naturais, sob o qual se podem dissimular vários estratos de significações "implícitas".

Assim, no texto analisado está dito que:

a) Os estudantes de Letras têm um perfil cultural que os identifica como sendo pobres ou miseráveis, filhos de analfabetos, com pouco domínio da leitura e da escrita e não são falantes da língua culta;

b) Os professores iludem os estudantes com o ensino que lhes oferecem;

c) Os formados em Letras saem do curso sem saber o básico da especificidade da área de formação;

d) O problema é não oferecermos aos alunos (esses de baixo conhecimento linguístico e literário) condições de se familiarizarem com o mundo acadêmico;

e) Precisamos resolver o problema da formação de professores de Português no Brasil;

f) As salas de aula hoje já são ocupadas por professores que mal sabem ler e escrever adequadamente;

g) Os docentes são muito cobrados, mas recebem pouca formação; e

h) Os professores não recebem uma formação decente.

Sabemos que as informações trazidas no texto, excetuando-se as generalizações, podem ser facilmente comprovadas com dados estatísticos oficiais - embora o próprio texto não os traga - e que outras leituras da área facilmente corroboram com o que foi denunciado pelo autor do texto. A compreensão do que está dito frequentemente depende de saberes elaborados a partir da leitura de outros textos. Durante a leitura do texto, o leitor 
realiza produções de sentido que o levam a estabelecer conexões intertextuais, afinal, como afirmou Foucault (2008, p. 26),

[...] as margens de um livro jamais são nítidas nem rigorosamente determinadas: além do título, das primeiras linhas e do ponto final, além de sua configuração interna e da forma que lhe dá autonomia, ele está preso em um sistema de remissões a outros livros, outros textos, outras frases: nó em uma rede.

Na leitura do texto analisado, por exemplo, o desconhecimento de produções como as de Freitas (2002), Gatti (2010) e Silva (2013), dentre outros, que ratificam os dados estatísticos sobre a formação dos graduandos em Letras e seu perfil cultural citado por Marcos Bagno, levaria qualquer leitor a interpretar seu texto como preconceituoso.

Quanto ao não-dito, percebemos que:

a) Ao comparar a questão discursiva com as queimadas da Amazônia, o autor diz que as consequências disso serão de uma proporção assustadora, pois além de perpassarem por questões ambientais, políticas, sociais e econômicas (como nas consequências das queimadas), a má formação dos professores de português gerará prejuízos intrínsecos, individuais e coletivos aos sujeitos sociais;

b) Os licenciados em Letras são "leigos diplomados";

c) $\mathrm{O}$ autor critica a falta de rigor epistemológico e como as coisas "correm soltas no curso", pois a pesquisa na área de Letras deveria produzir um saber rigoroso como o é todo saber científico;

d) Todos os estudantes de Letras ao fazerem matrícula deveriam estar aptos a aprender as especificidades da área;

e) Precisamos reformular o currículo do Curso de Letras de modo a começarmos de forma mais branda, com aprendizagens mais simples e só depois avançarmos para as mais complexas;

f) Os professores recebem pouco retorno de sua atuação profissional e não obtém qualidade de formação na mesma proporção em que são cobrados; e, por fim, mas não esgotando as demais possibilidades de análise discursiva,

h) A formação de professores de Letras é insatisfatória e cheia de lacunas.

Dessa maneira, para qualquer leitor - com ou sem conhecimento prévio da realidade da formação de professores de LP no Brasil - as representações imaginárias sobre o curso de Letras tendem a ser negativas: que neste curso não se ensina e/ou se aprende o 
que é necessário para a atuação profissional. A compreensão dos leitores, a partir do texto, vai caminhar na perspectiva de que a universidade, como lugar de formação de professores, vem se mostrando deficitária para tal função. O lugar social atribuído a esses graduandos em Letras - futuros docentes de Língua Portuguesa - é a escola pública ou particular que, ao contratá-los, corre o real risco de oferecer um ensino de má qualidade.

Em suma, observamos ao longo de todo o texto regularidades discursivas que denunciam a formação discursiva do autor: docente acadêmico do curso de Letras cujo viés ideológico é crítico e engajado em provocar mudanças nessa realidade. Seu texto é marcado por críticas ao modelo educacional cujos frutos são questionáveis e soma voz a outros pesquisadores da área pertencente à mesma formação discursiva do autor em questão. Ou seja, os enunciados dialogam entre si e fazem parte de um discurso acadêmico específico.

\section{A formação do professor de Língua Portuguesa: pontos em discussão}

A formação docente representa eixo central nos atuais debates pedagógicos, devido à magnitude do impacto que a educação gera numa sociedade. Um professor de escola pública que leciona nas condições atuais de ensino terá, ao final do seu magistério, impactado - positiviamente ou negativamente - milhares de vidas.

Os desafios a serem enfrentados na formação docente se relacionam com as demandas de uma sociedade em constante desenvolvimento, colocando o professor no centro das mudanças políticas, educacionais, sociais e culturais, exigindo-lhe um posicionamento progressista que demonstre capacidade tanto técnica (ter segurança dos conteúdos de sua área de estudo) quanto pedagógica (ser capaz de ensinar o que sabe). A realidade, no entanto, é a de que os cursos de formação docente, especialmente o curso de Letras, não têm tido êxito nesta tarefa. No excerto abaixo, Gatti (2016, p. 166) esclarece essa problemática:

Mesmo com avanços a partir de programas desenvolvidos na última década, a questão da formação dos professores tem sido um grande desafio para as políticas governamentais, e um desafio que se encontra também nas práticas formativas das instituições que os formam. Nas instituições formadoras, de modo geral, o cenário das condições de formação dos professores não é animador pelos dados obtidos 
em inúmeros estudos e pelo próprio desempenho dos sistemas e níveis de ensino, revelado por vários processos de avaliação ampla ou de pesquisas regionais ou locais. Reverter um quadro de formação inadequada não é processo para um dia ou alguns meses, mas para décadas.

A fim de preparar os docentes, as instituições de formação superior precisam repensar o seu papel e promover transformações estruturais, organizacionais e pedagógicas As adversidades não sanadas durante a formação do professor de LP, no futuro, certamente atingirão o seu lugar de atuação - a escola -, repercutindo numa educação básica de má qualidade em que alunos concluem o ensino médio como analfabetos funcionais: sabem decodificar as letras e sílabas, mas são incapazes de interpretar um texto. Esses mesmos alunos um dia chegarão às universidades e o ciclo se perpetua. Razão mais do que suficiente para que as instituições formadoras desses profissionais repensem, renovem e recriem seus currículos, a fim de resolver os problemas existentes, acompanhar as mudanças da atualidade, ampliando os conhecimentos e saberes dos que formam e dos que serão formados.

No texto em análise, Marcos Bagno assevera que os estudantes dos cursos de Letras saem do curso superior com uma formação caótica, pois se formam sem saber linguística, teoria, crítica literária e sem saber escrever um texto acadêmico. O autor mostra que os cursos de Letras do Brasil não estão formando adequadamente os acadêmicos, sinalizando a necessidade urgente de reformulação desses cursos.

Em estudo recente, Pires (2019) confirma isso. Ao avaliar os professores de Língua Portuguesa da educação básica de um município baiano, a pesquisadora constatou que cerca de 35\% deles não possuíam a formação específica. Este é um percentual grande, visto que temos em vigor um Plano Nacional de Educação que preconiza em sua Meta 15 assegurar que todos os professores da educação básica possuam formação específica de nível superior, obtida a partir do curso de licenciatura na área de conhecimento em que atuam. Assim, ressaltamos que é preciso não só formar professores, mas formar com qualidade, pois só diplomar professores não resolve os problemas, apenas adia a resolução.

Nóvoa (1992) oferece um outro ponto de vista sobre a questão ao afirmar que a formação docente tem desprezado o progresso individual desses sujeitos, causando um 
equívoco entre "formar" e "formar-se", desfavorecendo os fundamentos do processo educativo, o qual nem sempre irá ao encontro do desempenho individual do aluno em formação. A formação docente deve proporcionar aos futuros professores autonomia para que sejam capazes de resolver situações-problema que ocorrem diariamente, principalmente, as que requerem saberes e conhecimentos específicos de sua formação, tanto a que acontece individualmente quanto coletivamente.

Assim, este autor (1992, p. 25) acredita que "a formação deve estimular uma perspectiva crítico-reflexiva, que forneça aos professores meios de um pensamento autônomo e que facilite as dinâmicas de autoformação participada". Diante disso, a formação docente terá um retorno objetivo, proporcionando-lhes desenvolver atividades de maneira independente e inovadora, as quais venham a contribuir para qualidade do processo formativo e para a construção de sua identidade docente.

Parece-nos óbvio que o professor que ensina uma língua deva conhecer a língua que ensina, afinal, como ensinar algo que não se compreende, não se usa eficientemente, não se domina seus aspectos estruturais e funcionais? Ou ainda, como ensinar algo que não se sabe como se aprende, se não se conhece o processo de aquisição e domínio da linguagem? Ou seja, o professor que ensina uma língua precisa ter conhecimentos e saberes linguísticos para ensinar. Coadunamos, assim, com Cagliari $(2009,16)$, quando fala especificamente sobre o professor de Língua Portuguesa, este "[...] tem que ser um profissional competente, tem que conhecer profundamente a língua portuguesa. Como pode ensinar o que não sabe?” Além disso, em visão mais ampla e complexa, o que este professor ensina (certo ou errado), ensina para alguém, logo, este alguém irá reproduzir suas aprendizagens adiante.

Nessa perspectiva, entendemos que as reformas educacionais não têm sido suficientes para impactar os currículos dos cursos de Licenciatura em Letras. Gatti e Barretto (2009) assinalaram isso, apontando que é um problema também de outras licenciaturas. Assim, entendemos que a Língua Portuguesa é demasiadamente difícil e exige uma formação densa, com conhecimentos bem específicos. Com isso, os professores de LP se diferenciam de todos os outros, isto porque a língua é o seu objeto de comunicação e trabalho 
(ele usa a língua para ensinar) e é também o seu objeto de ensino (ele ensina essa mesma língua).

Compreendemos, então, que a docência exige um conjunto de competências e habilidade a serem desenvolvidas por quem quer que almeje essa nobre profissão. Assim, concordamos com Mizukami (2004, p. 38) quando diz que

[a] base do conhecimento para ensinar consiste de um corpo de compreensões, conhecimentos, habilidades e disposições que são necessários para que o professor possa propiciar processos de ensinar e de aprender, em diferentes áreas de conhecimento, níveis, contextos e modalidades de ensino. Esta base envolve conhecimentos de diferentes naturezas, todos necessários e indispensáveis para a atuação profissional. É mais limitada em cursos de formação inicial, e se torna mais aprofundada, diversificada e flexível a partir da experiência profissional refletida e objetivada. Não é fixa e imutável, implica construção contínua, já que muito ainda está para ser descoberto, inventado, criado.

De fato, a aprendizagem da docência perpassa por um conjunto de conhecimentos específicos da formação docente e do processo de ensinar e aprender. E esta é contínua, uma vez que também abarca saberes advindos da experiência, principalmente, de seus pares. Entendemos, assim, que dentro do que se propõe como formação docente, a universidade vem desempenhando sua função com qualidade gradual ascendente. Há deficiências e limitações? Sim, sem dúvida, mas há também formação. Acerca das limitações da universidade e da condição renitente de incompletude humana e, por isso, eterna busca pelo saber e aprender, Zeichner (1993, p. 17) elabora:

A Reflexão também significa o reconhecimento de que o processo de aprender a ensinar se prolonga durante toda carreira do professor e de que, independente do que fazemos nos programas de formação de professores e do modo como o fazemos, no melhor dos casos só poderemos preparar os professores para começarem a ensinar. Com o conceito de ensino reflexivo, os formadores de professores têm a obrigação de ajudar os futuros professores a interiorizarem, durante a formação inicial a disposição e a capacidade de estudarem a maneira como ensinam, e de melhorar com o tempo, responsabilizando-se pelo seu próprio desempenho profissional. 
Diante do exposto, percebemos que a formação profissional se dá em dois níveis: o formal, perpetrado pela escola e universidade, e o informal/pessoal, desempenhado pelo próprio sujeito no seio de suas experiências de vida em sociedade. Dessa forma, no que compete às instituições de ensino superior, formadora de formadores, constatamos que elas têm cumprido o seu papel de forma ainda insuficiente e não têm preparado seus futuros docentes para ensinar de fato.

Por outro lado, a má formação não pode ser justificativa ad infinitum para que o professor permaneça incapacitado. Uma vez identificada as lacunas formativas, cabe ao profissional buscar se aperfeiçoar e desenvolver as competências necessárias ao cargo que deseja desempenhar. Afinal, como disse Freire (1987), o conhecimento não é algo que se deposita nos homens, mas que com eles se constrói, envolvendo-se num processo contínuo de aprendizagem.

Ainda, ao refletirmos sobre o tema central do texto - a má qualidade dos cursos e profissionais de Letras do Brasil - e observarmos a relação direta feita por Bagno ao perfil da maioria dos seus estudantes, nos parece importante discutir, ainda que brevemente, a urgente necessidade de democratização do acesso aos principais bens culturais e à educação básica de qualidade.

A falta ou dificuldade de acesso aos bens culturais é um problema enfrentado por uma grande parcela da população brasileira, pobres em sua maioria. Em consonância com o que é apresentado por Bagno, Farias et al. (2009) mostraram dados de uma pesquisa da UNESCO de 2004 sobre a procedência dos professores brasileiros da Educação Básica: estes se consideram como sendo de classe média baixa ou pobres, com pais, em sua maioria, sem nível superior. Assim, são professores oriundos de extratos de baixa renda.

Quanto ao acesso aos bens culturais destes professores pesquisados pela UNESCO, observou-se baixa frequência destes ao cinema, à exposições em centros culturais, teatros e museus. $\mathrm{O}$ acesso à televisão ou à leitura de revistas também era baixo. Houve, ainda, aqueles que nunca tiveram acesso a alguns desses bens. Os autores citam, ainda, outras pesquisas cujos professores participantes não sabiam o que era o circo e não conheciam um teatro. 
Entendemos que a aproximação com os bens culturais se faz necessária para uma formação (inter)cultural, profissional e pessoal mais abundante e diversificada. $\mathrm{O}$ acesso a esses bens possibilita ascender o universo cultural dos professores, formar práticas sociais de contemplação do belo, de apreciação da produção cultural do seu próprio povo e das demais sociedades, desenvolver uma prática docente mais tolerante e intercultural e construir saberes que são, muitas vezes, expressos no processo de ensinar. Para um professor que ensina Português, a língua materna de um país tão rico e diversificado culturalmente, a construção desse universo cultural é, muitas vezes, determinante para o desenvolvimento eficiente do processo ensino-aprendizagem.

Desse modo, assentimos que o texto em análise é um texto político que põe em cheque questões sociais e educacionais de grande importância - a formação docente do professor de língua portuguesa e o ensino básico brasileiro - capaz de suscitar reflexões discursivas e ideológicas no seu leitor, sobretudo aquele que faz parte da comunidade discursiva abordada (aluno ou professor de Letras) levando-o a ponderar acerca de suas próprias ações formativas, bem como a (re)avaliar as políticas públicas educacionais adotadas em seu país.

\section{Considerações Finais}

Inserido na formação discursiva docente, o objetivo precípuo do texto de Bagno é o de trazer o alerta sobre a precariedade do ensino dos cursos de Letras e o quanto o ensino superior tem falhado em receber bem os alunos oriundos de contextos de aprendizagem que deixaram a desejar. Para isso, o autor lança mão de diversos termos chocantes e atinge seu objetivo de chamar atenção do leitor e da sociedade para a urgente necessidade de uma mudança de atitude nos cursos de graduação espalhados pelo Brasil, especialmente por parte da comunidade docente e do setor público responsável pelo currículo do curso de Letras.

Sabemos que as palavras são cheias de significado e a forma e o lugar onde são usadas levam a essa ou aquela interpretação. As escolhas lexicais do autor levaram-no à 
generalização (ao redigir frases como essa: "esses estudantes têm um histórico de letramento muito reduzido"), bem como conferiram ao seu texto um sentido dramático ao utilizar palavras que remetem a uma significação de urgência e emergência ("catástrofe, bomba-relógio, tragédia ecológica, urgentemente", por exemplo). Isso, definitivamente, influenciou a forma como os sentidos do texto foram produzidos.

Assim, a partir do exposto, percebemos que o texto de Bagno apresenta potencialidade de produção de grande impacto nos efeitos de sentido experienciados por cada leitor. Para nós, recém-licenciadas em Letras, o texto foi fonte de reflexão, análise e aprendizagem e nos ratificou a importância de o estudante de Letras, futuro professor de língua portuguesa, estar a par dos estudos discursivos e consciente do papel político-ideológico da linguagem. Pois é diante desta consciência que este profissional se saberá transmissor e receptor de ideologias, assim como reprodutor de discursos: uma consciência valiosa para a construção de uma aprendizagem e de uma docência crítica e reflexiva.

\title{
PORTUGUESE TEACHER TRAINING:
}

A TEXT ON DISCURSIVE ANALYSIS

\begin{abstract}
This article was conducted from the perspective of Bakhtinian Discourse Analysis (BAKHTIN, 2002) and Critical Discourse Analysis (FAIRCLOUGH, 1996, 2001) in dialogue with authors in the field of education. It is a discursive analysis of Marcos Bagno's opinion article entitled "The Catastrophe of Letters Programs", where we discuss the context of discursive production; discourse, its lexical choices and meaning effects; and the Portuguese teacher training. We seek to analyze the author's discourse from the harsh criticism he makes in the text against the teachers training in Letters programs, as well as to reflect on the current situation of teacher education and the teaching of Portuguese Language in Brazil. The analyzed text reaches its goal of attracting the target reader's attention and raises reflections from the said and unsaid present in it when analyzed from the explicit and implicit role in discourse (DUCROT, 1984).
\end{abstract}

KEYWORDS: Discourse; Teacher training; Portuguese language.

\section{REFERÊNCIAS}

BAGNO, Marcos. A catástrofe dos cursos de Letras. Publicado originalmente na Revista Caros Amigos, 2008. Disponível em:<http://marcosbagno.com.br/site/?page_id=464>. Acesso em: 20 de out. 2018.

BAKHTIN, Mikhail. Marxismo e Filosofia da Linguagem. 9a ed. São Paulo: Hucitec Annablume, 2002. 
BRANDÃO, Helena H. Analisando o discurso. In: Faculdade de Filosofia, Letras e Ciências Humanas (FFLCH) da Universidade de São Paulo (USP). São Paulo, 2005. Disponível em: < http://www.fflch.usp. br/dlcv/lport/pdf/brand001.pdf > Acesso em: 05 de Abr. de 2015 .

BRASIL. Presidência da República. Casa Civil. Subchefia para Assuntos Jurídicos. Decreto $n^{0}$ 6.755, de 29 de janeiro de 2009. Institui a Política Nacional de Formação de Profissionais do Magistério da Educação Básica, disciplina a atuação da Coordenação de Aperfeiçoamento de Pessoal de Nível Superior - CAPES no fomento a programas de formação inicial e continuada, e dá outras providências. Disponível em: < https://www.capes.gov.br/images/stories/download/legislacao/Decreto-6755-2009.pdf>. Acesso em: 31 de out. 2019.

CAGLIARI, Luiz Carlos. Alfabetização e linguística. 11. ed., São Paulo: Scipione, 2009.

DUCROT, Oswald. Referente. ENCICLOPÉDIA Einaudi: Linguagem e Enunciação. Lisboa: Imprensa Nacional - Casa da Moeda, 1984, v.2, p. 418-438.

FAIRCLOUGH, Norman. Language and Power. New York: Longman Inc., 1996. . Discurso e mudança social. Brasília: Ed. UNB, 2001.

FARIAS, Isabel Maria Sabino de et. al. Didática e docência: aprendendo a profissão. Brasília: Liber Livros, 2009.

FERRÉS, Joan. Televisão subliminar. Porto Alegre: Artmed, 1998.

FOUCAULT, Michel. A arqueologia do saber. Rio de Janeiro: Forense Universitária, 2008.

FREIRE, Paulo Reglus Neves. Pedagogia do Oprimido. 17. ed., Rio de Janeiro: Paz e Terra, 1987. Versão digital.

FREITAS, Helena Costa Lopes de. Formação de professores no Brasil: 10 anos de embate entre projetos de formação. Educação e Sociedade, Campinas, v. 23, n. 80, p. 136-167, setembro/2002.

GATTI, Bernardete A. Formação de professores no Brasil: características e problemas. Educação e Sociedade, Campinas, v. 31, n. 113, p. 1355-1379, out.-dez. 2010.

; BARRETTO, Elba Siqueira de Sá. Professores do Brasil: impasses e desafios. Brasília, DF: UNESCO, 2009.

Formação de professores: condições e problemas atuais. Revista Internacional de Formação de Professores (RIFP), Itapetininga, v. 1, n.2, p. 161-171, 2016.

KUMARAVADIVELU, B. A Linguística Aplicada na era da globalização. In: MOITA LOPES, L. P. da. (Org.) Por uma Linguistica Aplicada Indisciplinar. São Paulo: Parábola Editorial, 2008, p. 129-148. 
LEPSCHY, Giulio. Léxico. ENCICLOPÉDIA Einaudi: Linguagem e Enunciação. Lisboa: Imprensa Nacional - Casa da Moeda, 1984, v. 2, p. 156-178.

MIZUKAMI, Maria da Graça N. Aprendizagem da docência: algumas contribuições de L. S. Shulman. Educação (Santa Maria), Santa Maria, v. 29, n. 2, p. 33-49, 2004.

NÓVOA, António. Formação de professores e profissão docente. In: NÓVOA, António. (Org.). Os professores e sua formação. Lisboa: Dom Quixote, 1992.

ORLANDI, Eni Puccinelli. Educação em direitos humanos: um discurso. In: SILVEIRA, Rosa Maria et. al. (Org.) Educação em Direitos Humanos: fundamentos teórico-metodológicos. João Pessoa: Editora Universitária, 2007. P. 295-311.

PIRES, Maria das Graças Porto. Os saberes e não saberes de professores de Lingua Portuguesa: perspectiva formativa. Dissertação (Mestrado). Programa de Pós-Graduação em Educação: Universidade Federal da Bahia. Salvador-BA, 2019.

SILVA, David José de Andrade. Formação de professores de língua para a autonomia: o buraco é mais embaixo. Trabalhos em Linguística Aplicada, Campinas, n (52.1), p. 73-92, jan./jun. 2013.

ZEICHNER, Kenneth. A formação reflexiva de professores: idéias e práticas. Lisboa: Educa, 1993.

Recebido em: 03/11/2019.

Aprovado em: 20/05/2020. 